Тинина Людмила Павловна, доцент, Ангарский государственный технический университет, e-mail: tinina-lp@inbox.ru

Коновалов Юрий Васильевич, к.т.н., доцент, Ангарский государственный технический университет, e-mail: yrvaskon@mail.ru

Истратов Роман Сергеевич,

обучающийся, Ангарский государственный технический университет

ОПРЕДЕЛЕНИЕ ВРЕМЕНИ ДО НАСЫЩЕНИЯ ТРАНСФОРМАТОРОВ ТОКА, ПРИ КОТОРОМ ОБЕСПЕЧИВАЕТСЯ ПРАВИЛЬНОЕ ФУНКЦИОНИРОВАНИЕ БЫСТРОДЕЙСТВУЮЩИХ УСТРОЙСТВ РЕЛЕЙНОЙ ЗАЩИТЫ

Tinina L.P., Konovalov Yu.V., Istratov R.S.

\title{
DETERMINING THE TIME BEFORE SATURATION OF CURRENT TRANSFORM- ERS WHICH PROVIDES CORRECT FUNCTIONING FAST RELAY PROTECTION DEVICES
}

\begin{abstract}
Аннотация. Предлагается таблично-графический метод расчета времени насыщения, позволяющий оптимизировать процесс выбора трансформаторов тока и подключенных к ним устройств релейной защиты для обеспечения правильной их работы в переходных режимах, сопровождающихся в том числе и возникновением апериодической составляющей тока, минимизировать ошибки, опираясь на таблично-графическую визуализацию.

Ключевые слова: переходный режим, время насыщения, ток, апериодическая составляющая, таблично-графический метод, визуализация.

Abstract. A table-graphical method for calculating the saturation time is proposed, which allows to optimize the process of selecting current transformers and relay protection devices connected to them to ensure their correct operation in transient ones, accompanied, among other things, by the occurrence of an aperiodic current component, to minimize errors, relying on table-graphical visualization.

Keywords: transient mode, saturation time, current, aperiodic component, tabular-graphical method, visualization.

Энергетика России активно развивается. На вновь вводимых и реконструируемых объектах широко внедряются устройства релейной защиты (Р3) и автоматики, выполненные на микропроцессорной элементной базе, обладающие высокой многофункциональностью и рядом других, теперь уже неоспоримых преимуществ. Однако опыт эксплуатации быстродействующих микропроцессорных устройств выявил фракты неправильной их работы, которые приводили иногда к серьезным авариям с перерывом электроснабжения потребителей. Одной из причин явилось отсутствие в нормативно-технической документации требований по обеспечению техническими характеристиками трансформаторов тока (ТT) и подключенным к ним устройствам Р3 правильного функционирования в переходных режимах, связанных с насыщением трансформаторов тока.

В настоящее время данное требование нашло свое отражение в Правилах технологического функционирования электроэнергетических систем, утвержденных Постановлением правительства Российской Федерации № 937 от 13 августа 2018 г., в предварительном национальном стандарте РФ (ПНСТ 283-2018) «Трансформаторы измерительные часть 2 Технические условия на трансформаторы тока» [1] и ГОСТе Р58669-2019 «Единая энергетическая система и изолированно работающие энергосистемы. Релейная защита. Трансформаторы тока из-
\end{abstract}


мерительные индуктивные с замкнутым магнитопроводом для защиты. Методические указания по определению времени до насыщения при коротких замыканияX» [2].

Минэнерго России в целях исключения неправильной работы устройств Р3 в переходных режимах, сопровождающихся насыщением трансформаторов тока, рекомендует выполнять расчеты времени до насыщения трансформаторов тока для существующих быстродействующих устройств Р3 при строительстве и комплексном перевооружении объектов энергетики на этапе выполнения проектной документации [3]. И на основании выполненных расчетов времени до насыщения ТТ определять требования к техническим характеристикам устройств Р3, в части минимального необходимого времени достоверного измерения значения тока ТТ, при которых обеспечивается их правильное функционирование. Критерием может являться отключение короткого замыкания (КЗ) за время меньшее, чем рассчитанное время до насыщения ТТ.

Предлагается таблично - графический метод: вначале в таблицу вносятся исходные технические данные трансформаторов тока, затем определяется постоянная времени затухания, рассчитывается нагрузка во вторичных цепях трансформаторов тока. Возможность насыщения ТТ в установившемся режиме учитывается с помощью параметра $A$, отражающего соотношение между номинальными параметрами ТТ и реальными его параметрами в месте установки. При определении времени насыщения предварительно рассчитываются токи трехфазного КЗ, а для сетей с глухим заземлением нейтрали еще и токи однофазных К3. Расчет времени насыщения выполняют как аналитически, так и графически при наличии в токе КЗ апериодической составляющей с использование коэффиициента переходного режима.

Данный метод позволяет значительно упростить и ускорить процесс выбора ТТ и минимизировать ошибки, опираясь на таблично-графическую визуализацию. Математические выражения, кривые, определяющие содержание апериодической составляющей в первичном токе, достаточно единожды представить в программе EXCEL. Табличный вариант позволяет наглядно видеть изменение в расчетах при вариации входных величин и может являться шаблоном при выполнении дальнейших расчетов.

\section{ЛИТЕРАТУРА}

1. ПНСТ 283-2018. Предварительный национальный стандарте РФ «Трансформаторы измерительные. Часть 2. Технические условия на трансформаторы тока» Москва. Стандартинфрорм, 2018. [Электронный ресурc]. URL: https://docs.cntd.ru/document/1200161312 (обращение 09.03.2021).

2. ГОСТ Р 58669-2019 «Единая энергетическая система и изолированно работающие энергосистемы. Релейная защита. Трансформаторы тока измерительные индуктивные с замкнутым магнитопроводом для защиты. Методические указания по определению времени до насыщения при коротких замыканиях». 2007-2021, ФГУП. СТАНДАРТИНФОРМ. [Электронный ресурс]. URL: http://protect. gost.ru/document.aspx?control=7\&id=238273 (обращение 09.03.2021).

3. Королев Е.П., Либерзон Э.М. Расчеты допустимых нагрузок в токовых цепях релейной защиты. - М.: Энергия, 1980. - 208 с. 